\title{
Performance of Microfinance Institutions in Ethiopia: Integrating Financial and Social Metrics
}

\author{
Solomon Bizuayehu Wassie ${ }^{1,2, *}$, Hitoshi Kusakari ${ }^{1}$ and Masahiro Sumimoto $^{3}$ \\ 1 Department of Agricultural Engineering and Socio-Economics, Kobe University, 657-8501 Kobe, Japan; \\ frontier@kobe-u.ac.jp \\ 2 Department of Agricultural Economics, Bahirdar University, Bahirdar, Ethiopia \\ 3 Department of Bioproduction Science, Ishikawa Prefectural University, 921-8836 Nonoichi, Japan; \\ sumimoto@ishikawa-pu.ac.jp \\ * Correspondence: 147a171a@stu.kobe-u.ac.jp or sbizuayehu@gmail.com
}

Received: 1 March 2019; Accepted: 9 April 2019; Published: 11 April 2019

\begin{abstract}
Since their inception in the 1970s, microfinance institutions (MFIs) have received increasing attention both from policymakers and academic circles. Using unbalanced panel data (2000-2017) from Ethiopia, in this paper, we investigated the performance of MFIs and its determinants on the one hand and whether or not mission drift exists on the other hand. To this end, we employed seemingly unrelated regression (SUR) and fixed/random effect panel models. The results indicate that, based on different outreach and financial performance metrics, the MFIs in Ethiopia have good performance compared with those of the 10 biggest economies in Sub-Saharan Africa (SSA). The econometric estimation results show that asset holding and the yield on gross portfolio have a positive and significant effect on the social and financial performances of MFIs in Ethiopia. Furthermore, the number of loan officers, loan officer productivity, and personnel productivity have a positive and significant impact on the financial performance of MFIs. Our results also suggest that the null hypothesis-that MFIs are not shifting away from poorer clients-cannot be rejected, implying that there is no mission drift by MFIs in Ethiopia.
\end{abstract}

Keywords: microfinance; Ethiopia; social and financial performance; mission drift; SUR model; panel data regression

\section{Introduction}

Limited access to financial services is among the major problems impeding rural livelihood development (Hermes and Lensink 2007; Wijesiri et al. 2017). The problem is particularly severe in developing countries, such as Ethiopia, mainly for two reasons. First, most of the conventional banks in the country are concentrated in urban areas, while more than $80 \%$ of the population is rural. Second, whenever available, the formal banking sector systematically excludes the rural poor due to the higher screening, monitoring, and enforcement costs of providing a small loan. Moreover, most poor have few or no assets that can be secured by a bank as collateral (Shu and Oney 2014; Hermes and Lensink 2007; Cull et al. 2011). Thus, a considerable number (more than $80 \%$ ) of the poor in Ethiopia obtain financial services from informal lenders, who are able to enforce loan contracts but at a high interest rate (Demirguc-Kunt et al. 2018; Wolday 2004). However, the government is making efforts to curb the role of informal lenders through the support of microfinance institutions (MFIs). In recognition of this, the Ethiopian government issued the first microfinance legislation in 1996. Since then, the number of clients, volume of the loan portfolio, and savings of MFIs have been increasing (Wolday 2004).

The main distinctive characteristics of MFIs in the financial market include, but are not limited to, the following: (1) they provide financial services to the poor, who are usually not considered 
to be creditworthy by banks; and (2) they solve the problem of information asymmetry and ease collateral requirements by establishing strong personal relationships, which generates social collateral (Assefa et al. 2013; Postelnicu and Hermes 2018). Therefore, MFIs face the dual challenge of providing financial services to the poor (outreach) and attaining financial sustainability. There are two schools of thought concerning the ultimate goal of MFIs: welfarists and institutionalists. Welfarists argue that the essence of establishing MFIs is to serve the poor, and hence, they should focus on outreach, whereas institutionalists reemphasize that MFIs should be financially sustainable, even to serve the poor (Tsegaye 2009).

Arguably, providing financial services to the poor is too costly (Postelnicu and Hermes 2018), and hence, the focus on outreach will be at the expense of the firm's financial performance (Abate et al. 2014; Shu and Oney 2014; Hermes et al. 2011). Here, an empirical question to answer is whether MFIs with commercial motives drift from their original mission of providing financial services to the poor. More explicitly, given the increasing focus of MFIs on commercialization (Vanroose and D'Espallier 2013; Daher and Saout 2013), is there a "mission drift" or re-orientation from their original mission of serving the poor in pursuit of commercial viability? With this question in mind, we were therefore motivated to (i) evaluate the performance ${ }^{1}$ of MFIs based on the sector's overriding objectives-i.e., reaching as many clients as possible while remaining financially viable; (ii) investigate the driving factors of MFI performance with the aim of supporting the path forward for improving social and financial performance; and (iii) test the existence of mission drift in the case of Ethiopia.

Ethiopia presents an interesting case study, because, in the country, informal lenders dominate the financial sector-i.e., 80\% of the poor depend on informal lenders (Demirguc-Kunt et al. 2018)—suggesting that more can be achieved in terms of increasing the outreach of MFIs. In fact, we also have practical experience and access to supplementary data to evaluate the performance of MFIs in Ethiopia ${ }^{2}$. Lastly, perhaps more importantly, the issue is less studied in the Ethiopian context ${ }^{3}$. Admittedly, there are empirical studies on the performance of MFIs both in Ethiopia and elsewhere (Tsegaye 2009; Abate et al. 2014; Assefa et al. 2013; Servin et al. 2012; Kipesha 2013; Vanroose and D’Espallier 2013; Wolday 2004; Cull et al. 2007; Hermes et al. 2011). However, while some of the previous studies (Abate et al. 2014; Hermes et al. 2011; Kebede and Berhanu 2012) focus on a single performance indicator (cost efficiency), others are either dated studies using cross-sectional data or focus on cases of other countries.

Prior studies have analyzed the factors affecting the social and financial performance of MFIs (e.g., Hermes et al. 2011; Cull et al. 2007; Ahlin et al. 2011; Luzzi and Weber 2006). Among other factors, the age of the MFIs was found to have a positive and significant impact on the financial performance (Abate et al. 2014; Kipesha 2013; Vanroose and D'Espallier 2013; Cull et al. 2007) and social performance (Assefa et al. 2013; Vanroose and D'Espallier 2013) of MFIs. The size of the institutions is another factor driving the performance of MFIs. Specifically, bigger MFIs tend to have better financial performance (Vanroose and D'Espallier 2013; Luzzi and Weber 2006; Cull et al. 2007) and outreach (Assefa et al. 2013; Vanroose and D'Espallier 2013) than smaller MFIs. Studies analyzing the relationship between outreach and financial performance have shown mixed results. While Hermes et al. (2011) argued that there exists a tradeoff between outreach and (cost) efficiency, other empirical evidence shows that serving the poor and achieving financial viability can be attained concurrently (Cull et al. 2007; Kereta 2007; Tsegaye 2009). The other strand of the literature studies mission drift by MFIs (Mersland and

1 Organizational performance can be measured either using a goal-attainment perspective or a system approach (Pinz and Helmig 2014). In the context of this paper, the success of a firm is measured by its effort to attain its organizational goal-in this case, using social and financial metrics.

2 This research is part of our project on evaluating the performance of agricultural marketing and financial institutions in Ethiopia. As described in Section 2, while the data used in this paper is primarily from the Microfinance Information Exchange (MIX) database, the paper has benefited from the data collected by the Association of Ethiopian Microfinance Institute for treating missing values.

3 The performance of MFIs is non-negligibly driven by the surrounding macroeconomic and institutional environment. Thus, MFIs should be judged in context (Ahlin et al. 2011). In this regard, this study suffers less from unobservable country-level factors, yet we acknowledge the associated shortcoming in terms of understanding the issue from a broader perspective. 
Strøm 2010; Vanroose and D'Espallier 2013; Christen 2001; Cull et al. 2007). Using panel data, Mersland and Strøm (2010) investigated mission drift and found no evidence supporting the hypothesis that MFIs drift away from serving the poor. Another study in Latin America also found similar results (Christen 2001).

Building on previous studies, in this paper, we contribute the following to the current literature. First, this study evaluates the performance of MFIs by estimating unique performance metrics from multi-dimensional indicators, capturing the maximum possible information from the original variables. Specifically, we use principal component analysis (PCA) to create indexes, which are used as measures of the two primary objectives of MFIs, namely, serving the poor (social performance) and attaining sustainability (financial performance). Aggregating different outcome indicators into an index helps to easily comprehend the result. Second, with the a priori assumption that the social and financial performances of MFIs are not independent, this study uses a simultaneous equation model-i.e., a seemingly unrelated regression (SUR) model. Third, taking advantage of the panel data used in this study, we employed a random or fixed effect model to account for firm-specific omitted variables or unobservable factors (e.g., technological change) that could affect performance (Green 2008; Vanroose and D'Espallier 2013). Finally, the current research sheds light on the issue of mission drift, which is less studied in the Ethiopian context.

The remainder of the paper is structured as follows. Section 2 describes the data and estimation strategy employed in the study. Section 3 presents the result and discussion. The last section concludes the paper by highlighting the implications of this study.

\section{Data and Estimation Strategy}

\subsection{The Data}

The results of this paper are based on unbalanced panel data (2000-2017) of 15 microfinance institutions in Ethiopia. The data is primarily from the Microfinance Information Exchange (MIX) market database available online, but data from the Association of Ethiopian Microfinance Institution was consulted when necessary to fill gaps in the MIX data. The MIX market database-the largest data source on the finances of MFIs (Cull et al. 2011) —encompasses a wide range of information regarding MFIs, including, but not limited to, performance indicators, firm characteristics, infrastructure and human capital, asset and liability management, and types and composition of clients. The econometric estimation results of this study were based on a panel of 155 MFI-year observations, primarily from the MIX database. The same data source was also utilized to compare the performance of MFIs in Ethiopia with other countries and regions.

\subsection{Estimation Strategy}

This paper aims to investigate the performance of MFIs and its determinants on the one hand and whether or not mission drift exists on the other hand. To this end, we conducted three exercises. First, we evaluated the performance of MFIs in Ethiopia in comparison with other countries and regional average performances. Second, we estimated the performance metrics and examined the factors that drive the social and financial performances of MFIs in Ethiopia. Finally, we investigated whether or not mission drift exists with respect to Ethiopian MFIs.

We employed PCA to generate the social performance and financial performance metrics. PCA is a data reduction method used to re-express multivariate data with fewer dimensions. Explicitly, PCA reorients the multivariate data so that they can be summarized with relatively few "components" that capture the maximum possible information from the original outcome variables (Luzzi and Weber 2006). The selection of both outcome and explanatory variables used in this study was based on previous studies (Tsegaye 2009; Assefa et al. 2013; Rosenberg 2009; Vanroose and D'Espallier 2013; Ahlin et al. 2011; Cull et al. 2007; Luzzi and Weber 2006). Accordingly, we used a total of six outcome indicators, namely, number of borrowers, number of depositors, total gross loan portfolio (GLP), 
returns on asset (ROA), returns on equity (ROE), and financial self-sufficiency (FSS) to estimate the social and financial performance metrics. The definition and measurement of the variables used in this study are presented in Table A1.

The Kaiser-Meyer-Olkin (KMO) sample adequacy measure of the data (0.72) was found to be larger than the minimum threshold of 0.5 (Table A2). The appropriate number of factors to be used in the analysis-i.e., those with eigenvalues greater than one-was found to be two (Figure A1). While the first component alone explained $48 \%$ of the variance among the six indicators considered, the second component explained 38\%. Moreover, of the listed indicators above, the first three were positively loaded on the first component. The latter three were also positively loaded on the second component (Table A2). Hence, component 1 and component 2 estimates were used as a proxy for measuring social performance and financial performance, respectively. In the context of this study, social performance refers to outreach breadth.

Once the performance metrics were estimated, there were two possible options at our disposal: to estimate two independent equations for the two outcome variables or to estimate the two equations simultaneously. With the a priori assumption that there may be unobservable factors that affect both the social and financial performances of MFIs, we employed a SUR model. The SUR model allowed for the correlation of the error terms across equations (Tsegaye 2009). Denoting the performance or score of MFI i on dimension $\mathrm{j}=1,2$ by $S_{\mathrm{ji}}$, the SUR model can be specified as:

$$
S_{j i}=X_{j i} \beta_{j}+T_{j i} \gamma_{j}+\varepsilon_{j i}
$$

where $S_{\mathrm{ji}}$ is an index estimated from outcome indicators representing social performance $\left(S_{1 i}\right)$ and financial performance $\left(\mathrm{S}_{2 \mathrm{i}}\right), \mathrm{X}_{\mathrm{i}}$ is a row vector of MFI i's characteristics that explains social and financial performance, the vector $T_{i}$ denotes the fiscal year, $\beta$ and $\gamma$ are parameters to be estimated, and $\varepsilon_{j i}$ refers to the error terms. Here, we assume that the error terms are normally distributed with mean uncorrelated across observations but correlated across equations. More formally, $\mathrm{E}\left(\varepsilon_{1 \mathrm{i},} \varepsilon_{2 \mathrm{i}}\right)=\delta_{12} \neq 0$, and $\mathrm{E}\left(\varepsilon \mathrm{j}_{\mathrm{i}}\right)=0$ (Green 2008).

Taking advantage of the panel data used in this study, we estimated the random and/or fixed effect models to check the consistency of the results on the determinants of MFI performance in Ethiopia. Fixed effect approach is costly in terms of degrees of freedom lost. However, it is preferred as it relaxes the assumption of a random effect model-i.e., the individual effects are strictly uncorrelated with the other regressors (Green 2008). Therefore, an inevitable question here is which one should be used? To this end, we estimated both models and chose the one that best fit the data using the Hausman specification test. Following Green (2008), the basic framework for the specification of the fixed effect and random effect models is given as follows:

$$
\begin{aligned}
S_{i t} & =X^{\prime}{ }_{i t} \beta^{\prime}+Z^{\prime}{ }_{i} \alpha^{\prime}+\varepsilon^{\prime}{ }_{i t} \\
& =X^{\prime}{ }_{i t} \beta^{\prime}+C_{i}+\varepsilon^{\prime}{ }_{i t} .
\end{aligned}
$$

Suppose there are $\mathrm{K}$ regressors in $\mathrm{X}^{\prime}{ }_{\mathrm{it}}$, excluding a constant term. The individual effect is $Z^{\prime}{ }_{\mathrm{i}} \alpha^{\prime}$ where $Z_{i}^{\prime}$ contains a constant term and a set of firm-specific variables (e.g., legal status, bylaws, location). If $\mathrm{Z}_{\mathrm{i}}^{\prime}$ is unobserved but correlated with $\mathrm{X}^{\prime}{ }_{\mathrm{it}}$, then the fixed effect model is specified as:

$$
S_{i t}=X^{\prime}{ }_{i t} \beta^{\prime}+\alpha_{i}+\varepsilon^{\prime}{ }_{i t}
$$

where $\alpha_{i}=Z_{i}{ }_{i} \alpha^{\prime}$ embodies all the observable effects and specifies an estimable conditional mean. On the other hand, if the unobserved individual heterogeneity is assumed to be uncorrelated with the included variables, then the random effect model can be formulated as:

$$
\begin{gathered}
S_{i t}=X^{\prime}{ }_{i t} \beta^{\prime}+E\left[Z^{\prime}{ }_{i} \alpha^{\prime}\right]+\left\{Z^{\prime}{ }_{i} \alpha^{\prime}-E\left[Z^{\prime}{ }_{i} \alpha^{\prime}\right]+\varepsilon^{\prime}{ }_{i t}\right. \\
=X^{\prime}{ }_{i t} \beta^{\prime}+\alpha+\eta_{i}+\varepsilon^{\prime}{ }_{i t}
\end{gathered}
$$


where $\eta_{i}$ is a group-specific random element, similar to $\varepsilon^{\prime}$ it except that for each group there is a single draw that enters the regression identically in each period.

The last of the list of questions posited in Section 1 refers to mission drift. Mission drift can be measured by the increasing loan size of MFIs (Mersland and Strøm 2008). However, growth of average loan size does not necessarily mean that an MFI is suffering from mission drift. For example, as an MFI matures and growth slows, the average loan size of the same market will rise (Rosenberg 2009). Hence, over the course of time, successful MFIs will have clients who receive larger loans and will become less poor (Christen 2001). Yet, this is not mission drift. It is rather the successful attainment of an implicit objective of MFIs-i.e., poverty reduction. Mission drift is, therefore, a shift in the composition of new clients or a reorientation in favor of the so-called "less poor" (relatively better) of the existing clients rather than the overall improvement of the poverty condition of all the MFI's clients (Cull et al. 2007). A profit-oriented MFI that adopts a commercial approach may either increase the interest rate or reduce cost by lending larger loans to a few clients. In both cases, the less poor (as opposed to very poor) will qualify for a loan (Mersland and Strøm 2010). On the other hand, the profit motive may lead the MFI to reach new markets and to be more efficient (Christen 2001). Hence, the issue of mission drift is an empirical question specifically related to the commercialization of MFIs. In this study, we employ fixed and/or random effect models to examine if there exists mission drift by MFIs in Ethiopia. Intuitively, this analysis aims to examine whether or not their commercial motive has led MFIs to systematically ignore the poor and women. For this purpose, we use average loan/gross national income (GNI) and the percentage of women borrowers as measures of poor and women clients, respectively.

\section{Results and Discussion}

Table 1 describes the summary of the variables. We used a total of six outcome variables, mainly focusing on outreach and the sustainability of MFIs. The number of borrowers and depositors shows how many clients, on average, the MFI is serving. The MFIs in Ethiopia serve more than 85,000 clients. The other outreach performance indicator used in this study is the GLP (a proxy for the scale of their operation). On average, MFIs in Ethiopia have a GLP of 192 million Ethiopian birr. The FSS measures how well the MFI can cover its costs accounting for adjustments to operating revenues and expenses (Rosenberg 2009). Accordingly, $64 \%$ of the MFIs considered in this study are financially self-sufficient. The ROA and ROE are also sustainability/profitability measures indicating how well the MFI uses its assets to generate returns and how commercially viable it is, respectively (Rosenberg 2009; Daher and Saout 2015). The results demonstrate that each birr investment in the sector generates nearly 3.95 birr. The results also show that nearly half of the borrowers, on average, are women. Overall, for most outcome indicators, the standard deviations are larger than their corresponding mean, implying that there is considerable disparity in the performances of MFIs in the country (Tsegaye 2009). The majority $(51.6 \%)$ of the MFIs considered in this study are matured, whereas only $15 \%$ are new. On average, MFIs have 207 loan officers. The average number of clients served by the loan officer and personnel were also found to be 496 and 179, respectively. The yield on portfolio measures an MFI's ability to generate cash from interest, fees, and commissions on GLP, whereas portfolio to asset indicates the management's ability to allocate resources to the primary and most profitable activity of MFIs-making microloans (Rosenberg 2009; Barres et al. 2005). Accordingly, on average, the MFIs considered in this study devote nearly $70 \%$ of their assets to their primary purpose of making loans.

As outlined above, the aims of this study were threefold: (i) evaluating the performance of MFIs; (ii) examining the factors that drive the performance of MFIs; and (iii) testing whether or not mission drift exists with respect to Ethiopian MFIs. Accordingly, the following section discusses the performance of MFIs. The microfinance literature shows that measuring the performance of MFIs turns on evaluating their performance with respect to outreach, sustainability/profitability, and social impact (Tsegaye 2009; Servin et al. 2012; Rosenberg 2009; Vanroose and D'Espallier 2013). This paper, therefore, attempts to measure the performance of MFIs in Ethiopia and compare it with regional and country-specific performances mainly with respect to outreach breadth, outreach depth, and 
financial performance. Briefly, while outreach breadth measures the scale of operation and the number of clients being served, outreach depth refers the level of poverty of the clients. On the other hand, the financial performance metric objectively measures how successfully the MFIs recover their cost through operating income.

Table 1. Descriptive statistics.

\begin{tabular}{lcccccc}
\hline \multicolumn{1}{c}{ Variables } & Obs. & Mean & Std. Dev & Minimum & Maximum & Median \\
\hline Outcome indicators & & & & & & \\
Number of borrowers & 153 & 86.3 & 159.6 & 0.27 & 775.4 & 22.3 \\
Number of depositors & 153 & 88.5 & 238.0 & 0 & 2213.8 & 21.0 \\
GLP (Gross Loan Portfolio) & 153 & 192.3 & 483.8 & 0.18 & 3646.5 & 32.2 \\
FSS (Financial & 153 & 0.64 & 0.47 & 0 & 1 & 1 \\
Self-Sufficiency) & 153 & 1.37 & 7.19 & -69.7 & 16.7 & 2.07 \\
ROA (Returns on Asset) & 153 & 3.95 & 20.54 & -101.02 & 60.69 & 5.6 \\
ROE (Returns on Equity) & 152 & 57.56 & 28.58 & 2.62 & 189.4 & 59.1 \\
Average loan & 153 & 52.36 & 20.11 & 9.64 & 100 & 54.5 \\
Women borrowers & & & & & & \\
\hline Explanatory variables & 153 & & & & & 1 \\
Age & & 0.147 & & 0 & 1 & 0 \\
$\quad$ New & & 0.337 & & 0 & 1 & 1 \\
$\quad$ Young & 153 & 270.3 & 709.9 & 0.68 & 5485.1 & 38.7 \\
$\quad$ Matured & 149 & 0.207 & 0.39 & 0.002 & 2.32 & 0.06 \\
Asset & 144 & 0.496 & 0.74 & 0 & 9.06 & 0.37 \\
Loan officer & 152 & 0.179 & 0.16 & 0 & 2.05 & 0.16 \\
Loan officer productivity & 153 & 3.39 & 37.57 & 0 & 65.24 & 5.3 \\
Personnel productivity & 153 & 69.7 & 16.01 & 4.08 & 128.04 & 72.4 \\
Yield on gross portfolio & & & & & & \\
Portfolio to asset & & & & & & \\
\hline
\end{tabular}

Tables 2 and A3 present the performance of MFIs in Ethiopia in comparison with other regions and Sub-Saharan African (SSA) countries, respectively. While the variables used in the econometric analysis (Table A1) were measured in local currency, for consistency reasons, we used the United States dollar (USD) for the data reported in Table 2. Similarly, for ease of comparison across countries and regions, the values reported in Tables 2 and A3 are weighted averages based on the online MIX database. The number of borrowers and GLP are indicators that can be used to assess outreach breadth (Bibi et al. 2018). Accordingly, the average number of borrowers per MFI in Ethiopia $(86,200)$ is larger than that of all the regional averages except that of South Asia. Similarly, using the same metrics, MFIs in Ethiopia are the second largest amongst those of the 10 biggest economies in SSA (Table A3). On the contrary, the average GLP of MFIs in Ethiopia is limited to only 14.8 million USD, which is less than all the regional averages.

Table 2. Performance of microfinance institutions (MFIs) in Ethiopia: comparison with regional performance averages.

\begin{tabular}{|c|c|c|c|c|c|}
\hline Country/Region & $\begin{array}{l}\text { Number of } \\
\text { Borrowers } 1\end{array}$ & GLP (million \$) & $\begin{array}{c}\text { Average } \\
\text { Loan/GNI }\end{array}$ & $\begin{array}{l}\text { \% Female } \\
\text { Borrower }\end{array}$ & OsS \\
\hline Ethiopia & 86,213 & 14.84 & $58.22 \%$ & $45.76 \%$ & $145.73 \%$ \\
\hline Africa & 22,383 & 21.61 & $72.58 \%$ & $45.01 \%$ & $116.66 \%$ \\
\hline East Asia and Pacific & 84,489 & 103.56 & $55.26 \%$ & $43.65 \%$ & $109.22 \%$ \\
\hline $\begin{array}{c}\text { Eastern Europe and Central } \\
\text { Asia }\end{array}$ & 10,875 & 35.84 & $101.53 \%$ & $39.88 \%$ & $114.89 \%$ \\
\hline Middle East and North Africa & 40,025 & 20.85 & $18.50 \%$ & $57.63 \%$ & $119.87 \%$ \\
\hline South Asia & 217,941 & 45.15 & $16.86 \%$ & $78.18 \%$ & $120.58 \%$ \\
\hline World & 68,211 & 51.44 & $50.19 \%$ & $51.82 \%$ & $115.99 \%$ \\
\hline
\end{tabular}

${ }^{1}$ The number of borrowers is rounded to the nearest whole number. OSS = Operational Self-Sufficiency. GNI $=$ Gross National Income. 
The other important aspect of outreach measures the poverty level of clients. Apparently, measuring a client's poverty level is expensive and requires sophisticated indicators. However, the average loan/GNI can be a rough proxy to measure outreach depth and hence the poverty status of clients, because better off clients tend to be uninterested in smaller loans (Rosenberg 2009). Similarly, the percentage of female borrowers refers to loan distribution to the minority group of society (Mersland and Strøm 2010; Bibi et al. 2018). In this regard, the smaller ratio of the average loan/GNI implies that MFIs are serving the relatively poor in the country. Accordingly, Ethiopian MFIs serve relatively poorer clients compared with the African regional average and that of Eastern Europe and Central Asia. Following the target market classification of MIX , Ethiopian MFIs target "broad markets"-i.e., depth from $20 \%$ to $149 \%$. Of the 10 biggest economies in SSA, while MFIs in South Africa serve the poorest (depth $=5.47 \%$ ), MFIs in Kenya serve relatively better off clients (depth $=120 \%$ ) (Table A3).

The last, but in no sense the least, performance indicator measures the ability of an MFI to recover its costs through operating income. The average operational self-sufficiency of Ethiopian MFIs is $145 \%$, i.e., higher than all the regional averages. Hence, ceteris paribus, Ethiopian MFIs have relatively higher financial performance. As shown in Table A3, of the 10 biggest economies in SSA, MFIs in Ethiopia, followed by those in the Sudan and Nigeria, have the highest operational self-sufficiency (OSS), implying that they are relatively more profitable.

Table 3 presents different estimation results on the determinants of performance for MFIs in Ethiopia. The first panel of Table 3 shows the SUR model estimation, while the second and the third panel results were estimated by random effect and fixed effect models, respectively. The overall goodness of fit of the SUR model shows that the model significantly explained the variation in the performance of MFIs in Ethiopia. The multicollinearity test result presented in Table A4 also shows that there is no series multicollinearity in the explanatory variables-i.e., it is below the threshold level of 10. However, the Breusch-Pagan test of independence result revealed that we cannot reject the hypothesis that the errors are not correlated across equations $\left(\mathrm{Chi}^{2}=0.43, p\right.$-value $\left.=0.83\right)$. In other words, there is no significant unobserved factor that affects both the social and financial performances of MFIs. This result suggests that pursuing both social and financial performances is possible (Tsegaye 2009; Cull et al. 2007). On the other hand, the result suggests that, in this particular case, pooled ordinary least square estimation could have given a similar result (Vanroose and D'Espallier 2013). The Hausman specification test result shows that random effect (the second panel of Table 3) and fixed effect (the third panel of Table 3) models fit the data better than the pooled regression model (the results are not reported here for brevity but are available upon request). Hence, the following discussions are mainly based on the second and third panels of Table 3.

The second panel of Table 3 presents the estimated results on the factors affecting the social performance of MFIs in Ethiopia. The results show that while MFIs with larger assets have better social performance, there is no detectable difference among new, young, and matured MFIs. The positive effect of asset holding on the social performance or outreach of MFIs is as expected and consistent with previous studies (Vanroose and D'Espallier 2013; Bibi et al. 2018; Daher and Saout 2015). Similarly, the number of loan officers has a positive and significant impact on social performance. Intuitively, ceteris paribus, the greater the number of loan officers, the larger the domain the MFI can operate (Luzzi and Weber 2006). Loan officer and personnel productivities also have positive and significant impacts on social performance. These results suggest that increasing the number and improving the quality of human capital, e.g., through innovation and technology, could help MFIs in Ethiopia to enhance their social performance. The yield on the gross portfolio is another important variable affecting outreach performance. The yield on gross portfolio measures the firm's ability to generate cash, which could increase the loanable fund and hence the social performance. In fact, previous studies have also found similar results (Assefa et al. 2013; Cull et al. 2007).

4 https://www.themix.org/glossary. 
Table 3. Factors driving the performance of MFIs in Ethiopia.

\begin{tabular}{|c|c|c|c|c|}
\hline \multirow{2}{*}{ Variable } & \multicolumn{2}{|c|}{$\begin{array}{c}\text { (1) } \\
\text { SUR Estimation }\end{array}$} & \multirow{2}{*}{$\begin{array}{c}(2) \\
\text { Social Performance } \\
\left(\text { RE) }{ }^{1}\right.\end{array}$} & \multirow{2}{*}{$\begin{array}{c}\text { (3) } \\
\text { Financial } \\
\text { Performance (FE) }{ }^{1}\end{array}$} \\
\hline & $\begin{array}{c}\text { Social } \\
\text { Performance }\end{array}$ & $\begin{array}{c}\text { Financial } \\
\text { Performance }\end{array}$ & & \\
\hline \multicolumn{5}{|l|}{ Age $($ reference $=\mathrm{New})$} \\
\hline Young & $-0.09(0.09)$ & $0.42(0.46)$ & $-0.12(0.09)$ & $0.93(0.45)^{* *}$ \\
\hline Matured & $-0.03(0.11)$ & $-0.62(0.55)$ & $-0.11(0.12)$ & $0.82(0.64)$ \\
\hline Asset & $0.001(0.00)^{* * *}$ & $0.0004(0.0003)$ & $0.001(0.00)^{* * *}$ & $0.0008(0.0004) *$ \\
\hline Loan officer & $1.40(0.11)^{* * *}$ & $0.07(0.56)$ & $1.58(0.17)^{* * *}$ & $-1.55(1.39)$ \\
\hline Loan officer productivity & $0.21(0.07)^{* * *}$ & $-0.56(0.34)$ & $0.16(0.08)^{* *}$ & $-0.17(0.41)$ \\
\hline Personnel productivity & $0.36(0.15) * *$ & $-0.28(0.74)$ & $0.32(0.15) * *$ & $0.20(0.65)$ \\
\hline Yield on gross portfolio & $0.002(0.001)^{* * *}$ & $0.01(0.003)^{* * *}$ & $0.002(0.00)^{* * *}$ & $0.006(0.003) *$ \\
\hline Portfolio to asset & $0.002(0.002)$ & $0.01(0.006) *$ & $0.02(0.02)$ & $0.01(0.01)$ \\
\hline Fiscal year & $0.002(0.01)$ & $-0.04(0.05)$ & $0.12(0.11)$ & $-0.14(0.06)^{* *}$ \\
\hline Constant & $-4.45(19.74)$ & 79.97 (99.69) & $-25.06(23.32)$ & $284.0(121.2)^{* *}$ \\
\hline Observations & 140 & 140 & 140 & 140 \\
\hline $\mathrm{Chi}^{2}$ & $5379.7^{* * *}$ & $35.61^{* * *}$ & $3185.33^{* * *}$ & $25.80^{* * *}$ \\
\hline R-square & 0.91 & 0.21 & 0.95 & 0.16 \\
\hline \multicolumn{2}{|c|}{ Breusch-Pagan test of independence $\left(\mathrm{Chi}^{2}\right)$} & 0.043 & & \\
\hline
\end{tabular}

The third panel of Table 3 presents results on the determinants of financial performance. The age of MFIs could have a positive or negative effect on financial performance. One possible explanation for the positive effect of age on financial performance is that firms learn over time. On the other hand, older firms may face liability obsolescence and tend to be inflexible to the changing business environment (Coad et al. 2013). Extending further, some studies have shown that age has a nonlinear relationship with financial performance (Vanroose and D'Espallier 2013; Ahlin et al. 2011). In this regard, the results of this study show that young MFIs have better financial performance than new ones. However, there is no detectable difference between the financial performance of matured and new firms.

Th asset holding of MFIs is also among the driving factors of financial performance. Our results reveal that asset holding has a positive and significant impact on the firm's financial performance, possibly because larger firms can benefit from economies of scale (Kipesha 2013). Similarly, higher yield on the gross portfolio is significantly associated with better financial performance. This result shows that an MFI's ability to manage its loan portfolio significantly improves its financial performance. These results are consistent with those of prior studies (Cull et al. 2007; Vanroose and D'Espallier 2013).

The commercialization of MFIs is reflected by their strong financial performance (Christen 2001). Hence, Table 4 presents the relationship between financial performance-a proxy for the commercial motive of MFIs - and outreach depth. We used average loan/GNI as a measure of how poor the clients are relatively and the percentage of women borrowers to refer to how many of the clients belong to the minority social group (Bibi et al. 2018; Mersland and Strøm 2010). Here, the lower (higher) the average loan/GNI (percentage of women borrowers), the deeper the outreach. The first panel of Table 4 shows that the main effect of financial performance (i.e., FSS) had no impact on outreach depth. Similarly, the interaction effects of FSS with age and GLP were insignificant. The overall impact of financial performance was tested using a joint test. The test result shows that the null hypothesis-that the overall impact (the main and interaction effects) of a financial performance is equal to zero-cannot be rejected $\left(\mathrm{Chi}^{2}=0.08, p\right.$-value $\left.=0.773\right)$, implying that there is no evidence of mission drift. 
Table 4. Outreach depth and financial sustainability: test for mission drift.

\begin{tabular}{|c|c|c|c|c|}
\hline \multirow[t]{2}{*}{ Variable } & \multicolumn{2}{|c|}{$\begin{array}{c}\text { (1) } \\
\text { Average Loan/GNI }\end{array}$} & \multicolumn{2}{|c|}{$\begin{array}{c}(2) \\
\text { Percentage of Woman Borrowers }\end{array}$} \\
\hline & Coeff. & Std. Err & Coeff. & Std. Err \\
\hline FSS & -8.22 & 10.36 & $-19.44^{* *}$ & 8.28 \\
\hline \multicolumn{5}{|l|}{ Age $($ reference $=\mathrm{New})$} \\
\hline Young & 11.98 & 10.75 & $-15.02 *$ & 8.50 \\
\hline Matured & 3.17 & 13.01 & $-23.32 * *$ & 9.64 \\
\hline \multicolumn{5}{|l|}{ FSS \# Age } \\
\hline FSS $\times$ Young & -1.36 & 12.07 & 11.40 & 9.68 \\
\hline FSS $\times$ Matured & 13.65 & 11.99 & $22.67 * *$ & 9.52 \\
\hline GLP (measure of size) & $0.02 * *$ & 0.01 & 0.01 & 0.01 \\
\hline FSS $\times$ GLP & -0.05 & 0.01 & -0.009 & 0.007 \\
\hline Portfolio to asset & $0.49^{* * *}$ & 0.13 & $-0.23 * *$ & 0.10 \\
\hline Fiscal year & $-4.92 * * *$ & 0.90 & 0.49 & 0.64 \\
\hline Constant & $9897.5^{* * *}$ & 1820.3 & -889.9 & 1281.1 \\
\hline Observations & 153 & & 154 & \\
\hline Wald $\mathrm{Chi}^{2}$ & $7.35 * * *$ & & $21.10^{* *}$ & \\
\hline Joint test of FSS $=0\left(\mathrm{Chi}^{2}\right)$ & 0.08 & & 1.73 & \\
\hline
\end{tabular}

On the other hand, the second panel of Table 4 shows that the main effect of financial performance (i.e., FSS) was negative and significant, suggesting that MFIs, which are financially self-sufficient, tend to have a lower proportion of women borrowers. However, the interaction effect shows that, when they are financially self-sufficient, matured MFIs tend to have a higher proportion of women borrowers than new MFIs. Overall, the joint test result reveals that the total effect of financial performance on outreach depth was not significantly different from zero $\left(\mathrm{Chi}^{2}=1.73, p\right.$-value $\left.=0.118\right)$. Hence, the results suggest that there is not enough evidence supporting the existence of mission drift in Ethiopian MFIs. This result is consistent with the findings of Cull et al. (2007).

\section{Conclusions}

Measuring the performance of MFIs is important in order to make reforms, when necessary, to meet organizational goals. Similarly, identifying the factors that drive their performance is also necessary to determine the path forward. While the main goal of this research was to investigate the performance of MFIs and its determinants in Ethiopia, the paper specifically addressed the following research questions: How well do MFIs in Ethiopia perform in terms of attaining their social and financial goals? Are MFIs serving the poor? Which factors drive the performance of MFIs? Is there mission drift by MFIs in Ethiopia?

Overall, Ethiopian MFIs have good performance with respect to outreach compared with both the regional average performances and those of the 10 biggest economies in Sub-Saharan Africa. The financial performance measure also shows that MFIs in Ethiopia have the highest operational self-sufficiency compared with all the regional averages. The econometric estimation results show that asset holding, the number of loan officers, loan officer productivity, personnel productivity, and the yield on gross portfolio have a significant effect on the social performance of MFIs in Ethiopia. On the other hand, age, asset holding, and the yield on gross portfolio were found to have positive and significant impacts on the financial performance of MFIs. Finally, we shed light on the debate regarding whether MFIs are shifting away from poorer clients due to their increasing focus on commercialization. 
To this end, we used two measures of outreach depth and found no evidence that the overall impact of financial performance (a proxy for the commercialization motives of MFIs) is related to outreach depth. Hence, the results suggest that there is no mission drift by MFIs in Ethiopia.

To sum up, based on the results of the study, the following concluding remarks are presented. First, relatively, MFIs in Ethiopia attain their goal of serving the poor with higher and deeper outreach. Second, there is no evidence supporting the existence of mission drift, suggesting that MFIs in Ethiopia do not shift from their original goal of serving the poor. Third, cultivating both the social and financial performances of MFIs in Ethiopia is possible. Hence, MFIs in Ethiopia are encouraged to exert more effort towards improving their social performance. To this end, efforts to meet their social obligations can be attained by increasing the number of loan officers and improving their productivity-e.g., by adopting innovative approaches that ease the monitoring and evaluation of borrowers and outstanding loans, encourage the sharing of experiences to learn from success stories, and promote practical training.

We acknowledge that this research has the following limitations. First, there are MFIs that are not accounted for mainly due to lack of data. Hence, the result of this study cannot be generalized for all MFIs in Ethiopia. Second, using average loan size as a measure of poverty has been criticized in the literature. We have used the average loan size as a percentage of GNI to infer how far down the MFIs reach with respect to the national income distribution. However, more rigorous measures of client poverty may be more meaningful when they are available. Third, similar to other previous studies, there was insufficient exogenous variation in key variables to estimate causal impacts; therefore, the estimation results should be interpreted carefully. Despite the outlined shortcomings, the current paper contributes to the literature in two ways. First, this study contributes to the scarce literature on the performance of MFIs in general and the issue of mission drift by MFIs in the Ethiopian context, in particular. Second, methodologically, the study employed the SUR model together with fixed and/or random effect models and chose the most robust estimation result based on the appropriate tests. Lastly, we suggest future research to combine household data with MFI-level data to examine the actual impact of MFIs using direct measures of clients' poverty status and welfare (e.g., consumption expenditure).

Author Contributions: Conceptualization, S.B.W, H.K. and M.S.; methodology, S.B.W, H.K. and M.S.; data curation, S.B.W; software, S.B.W; validation, S.B.W, H.K. and M.S.; formal analysis, S.B.W; investigation S.B.W, H.K. and M.S.; resources, S.B.W, H.K. and M.S.; writing-original draft preparation, S.B.W, H.K. and M.S.; writing-review and editing, S.B.W, H.K. and M.S.

Funding: This research received no external funding.

Conflicts of Interest: The authors declare no conflict of interest.

\section{Appendix A}

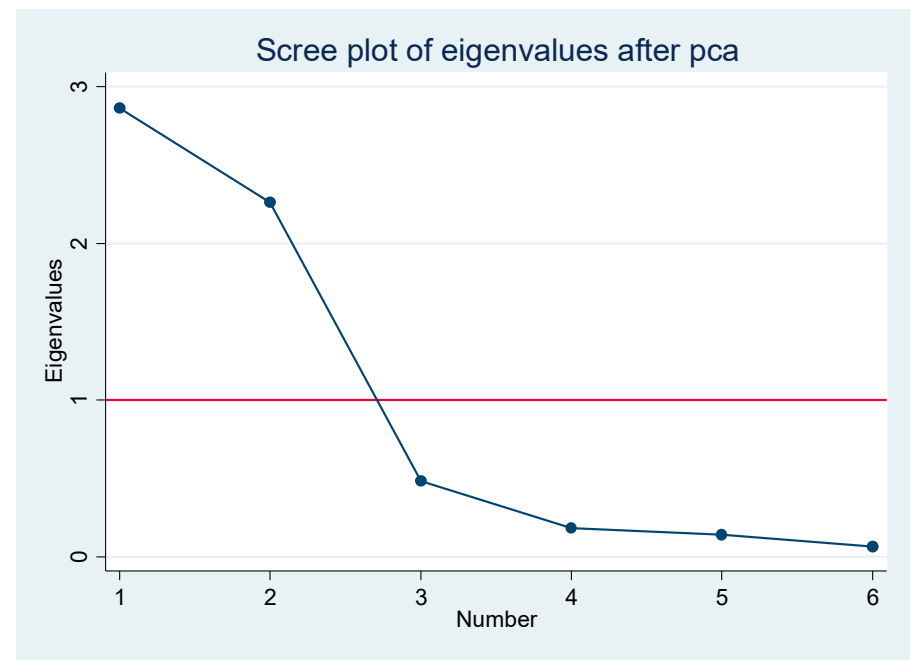

Figure A1. Scree plot of eigenvalues. PCA: principal component analysis. 
Table A1. Definition and measurement of variables.

\begin{tabular}{|c|c|}
\hline Variables & Definition and Measurement of Variables ${ }^{1}$ \\
\hline \multicolumn{2}{|l|}{ Outcome indicators } \\
\hline Performance score $\left(\mathrm{S}_{\mathrm{j}}\right)$ & $\begin{array}{l}\text { Indexes estimated from outcome indicators representing social } \\
\text { performance }\left(S_{1}\right) \text { and financial performance }\left(S_{2}\right) \text {. }\end{array}$ \\
\hline Number of borrowers & Number of active borrowers (thousands) \\
\hline Number of depositors & Number of active depositors (thousands) \\
\hline GLP & Total outstanding principal due for all client loans (million birr) \\
\hline FSS & $=1$ if financially self-sufficient and 0 otherwise \\
\hline ROA & $=[$ Net operating income, less Taxes/Average assets $] \times 100$ \\
\hline ROE & $=[$ Net operating income, less Taxes/Average equity $] \times 100$ \\
\hline Average loan & An average loan per client divided by GNI per capita \\
\hline Women borrowers & Percentage of women borrowers \\
\hline \multicolumn{2}{|l|}{ Explanatory variables } \\
\hline \multirow[t]{3}{*}{ Age } & Firm age $=1$ if new ( $1-4$ years $)$ \\
\hline & Firm age $=2$ if young ( $5-8$ years) and \\
\hline & Firm age $=3$ if matured ( $>8$ years) \\
\hline Asset & Total asset (millions of birr) \\
\hline Loan officer & The number of employees mainly managing client loans (thousands) \\
\hline Loan officer productivity & Total number of borrowers divided by loan officers (thousands) \\
\hline Personnel productivity & Total number of borrowers divided by total number of staff (thousands) \\
\hline Yield on gross portfolio & $=[$ Financial revenue/average gross loan portfolio $] \times 100(\%)$ \\
\hline Portfolio to asset & $=[$ Gross loan portfolio/total asset $] \times 100(\%)$ \\
\hline
\end{tabular}

Table A2. PCA estimates and diagnostics tests.

\begin{tabular}{|c|c|c|c|c|c|}
\hline \multirow{2}{*}{ Components } & \multirow{2}{*}{ Eigenvalue } & \multirow{2}{*}{$\begin{array}{l}\text { Proportion } \\
\text { Explained }\end{array}$} & \multicolumn{2}{|c|}{ Rotated Components ${ }^{1}$} & \multirow{2}{*}{ KMO } \\
\hline & & & Component 1 & Component 2 & \\
\hline $\begin{array}{l}\text { Number of } \\
\text { borrowers }\end{array}$ & 2.86 & 0.48 & 0.569 & & 0.84 \\
\hline $\begin{array}{l}\text { Number of } \\
\text { depositors }\end{array}$ & 2.26 & 0.38 & 0.577 & & 0.74 \\
\hline $\begin{array}{c}\text { Gross loan } \\
\text { portfolio }\end{array}$ & 0.48 & 0.08 & 0.585 & & 0.69 \\
\hline FSS & 0.18 & 0.03 & & 0.592 & 0.64 \\
\hline $\mathrm{ROA}$ & 0.14 & 0.02 & & 0.607 & 0.61 \\
\hline ROE & 0.07 & 0.01 & & 0.529 & 0.84 \\
\hline Rho & & 0.85 & & & \\
\hline Overall KMO & & & & & 0.72 \\
\hline
\end{tabular}

${ }^{1}$ We used oblique (promax rotation) rotation method. KMO refers to Kaiser-Meyer-Olkin and Rho is a parameter measuring the variance explained by the first two components.

Table A3. Performance of MFIs in the 10 biggest economies of Sub-Saharan Africa (SSA).

\begin{tabular}{cccccc}
\hline Country & Borrowers $^{2}$ & GLP (million \$) & $\begin{array}{c}\text { Average } \\
\text { Loan/GNI }\end{array}$ & $\begin{array}{c}\text { Female } \\
\text { Borrowers }\end{array}$ & OSS \\
\hline Angola & 9798 & 7.40 & $27.74 \%$ & $56.76 \%$ & $113.40 \%$ \\
Congo, Dem. Republic & 5980 & 13.59 & $57.61 \%$ & $47.86 \%$ & $89.36 \%$ \\
Cote d'Ivoire & 4850 & 8.90 & $109.13 \%$ & $27.37 \%$ & $90.98 \%$ \\
Ethiopia & 86,213 & 14.84 & $58.22 \%$ & $45.76 \%$ & $145.73 \%$ \\
Ghana & 11,463 & 8.54 & $41.92 \%$ & $59.31 \%$ & $108.26 \%$ \\
Kenya & 45,304 & 80.26 & $120.10 \%$ & $46.33 \%$ & $124.72 \%$ \\
Nigeria & 47,844 & 47.83 & $15.00 \%$ & $75.00 \%$ & $132.94 \%$ \\
South Africa & 96,472 & 127.00 & $5.47 \%$ & $36.76 \%$ & $116.33 \%$ \\
Sudan & 8673 & 11.33 & $46.50 \%$ & $57.66 \%$ & $141.00 \%$ \\
Tanzania & 20,523 & 54.73 & $80.67 \%$ & $62.25 \%$ & $122.38 \%$ \\
\hline
\end{tabular}

Source: MIX market database. ${ }^{1}$ The 10 biggest economies in SSA were selected based on World Bank database (https://data.worldbank.org/indicator/NY.GDP.MKTP.CD?locations=ZG\&year_high_desc=true). ${ }^{2}$ The number of borrowers is rounded to whole numbers. 
Table A4. Multicollinearity test: Variance inflation factor (VIF).

\begin{tabular}{ll}
\hline \multicolumn{1}{c}{ Variables } & VIF \\
\hline Age & \\
Young & 3.40 \\
Matured & 5.36 \\
Asset & 4.51 \\
Loan officer & 4.37 \\
Loan officer productivity & 1.39 \\
Personnel productivity & 1.21 \\
Yield on gross portfolio & 1.08 \\
Portfolio to asset & 1.34 \\
Fiscal year & 2.53 \\
\hline Total & 2.80 \\
\hline
\end{tabular}

\section{References}

Abate, Gashaw Tadesse, Carlo Borzaga, and Kindie Getnet. 2014. Cost-Efficiency and Outreach of Microfinance Institutions: Trade-Offs and the Role of Ownership. Journal of International Development 26: 923-32. [CrossRef] Ahlin, Christian, Jocelyn Lin, and Michael Maio. 2011. Where Does Microfinance Flourish? Microfinance Institution Performance in Macroeconomic Context. Journal of Development Economics 95: 105-20. [CrossRef]

Assefa, Esubalew, Niels Hermes, and Aljar Meesters. 2013. Competition and the Performance of Microfinance Institutions. Applied Financial Economics 23: 767-82. [CrossRef]

Barres, Isabelle, Tillman Bruett, Lynne Curran, Ana Escalona, Elena Nelson, Dan Norell, Beth Porter, Blaine Stephens, and Maria Stephens. 2005. Measuring the Performance of Microfinance Institutions: A Framework for Reporting, Analysis, and Monitoring. Edited by Tillman Bruett. The SEEP Network. Washington: The SEEP Network.

Bibi, Uzma, Hatice Ozer Balli, Claire D. Matthews, and David W. L. Tripe. 2018. New Approaches to Measure the Social Performance of Microfinance Institutions (MFIs). International Review of Economics and Finance 53: 88-97. [CrossRef]

Christen, Robert. 2001. Commercialization and Mission Drift: Transformation in Latin America. No. 5. Washington: CGAP (Consultative Group to Assist the Poor), p. 24.

Coad, Alex, Agustí Segarra, and Mercedes Teruel. 2013. Like Milk or Wine: Does Firm Performance Improve with Age? Structural Change and Economic Dynamics 24: 173-89. [CrossRef]

Cull, Robert, Asli Demirgüç-kunt, and Jonathan Morduch. 2007. Financial Performance and Outreach: A Global Analysis of Leading Microbanks. The Economic Journal 117: 107-33. [CrossRef]

Cull, Robert, Asli Demirgüç-Kunt, and Jonathan Morduch. 2011. Does Regulatory Supervision Curtail Microfinance Profitability and Outreach? World Development 39: 949-65. [CrossRef]

Daher, Lâma, and Erwan Le Saout. 2013. Microfinance and Financial Performance. Strategic Change 22: 31-45. [CrossRef]

Daher, Lâma, and Erwan Le Saout. 2015. The Determinants of the Financial Performance of Microfinance Institutions: Impact of the Global Financial Crisis. Strategic Change 24: 131-48. [CrossRef]

Demirguc-Kunt, Asli, Leora Klapper, Dorothe Singer, Saniya Ansar, and Jake Hess. 2018. The Global Findex Database 2017: Measuring Financial Inclusion and the Fintech Revolution. Washington: The World Bank. [CrossRef]

Green, H. William. 2008. Econometric Analysis, 6th ed. Upper Saddle River: Pearson Prentice Hall.

Hermes, Niels, and Robert Lensink. 2007. The Empirics of Microfinance: What Do We Know? The Economic Journal 117: 1-10. [CrossRef]

Hermes, Niels, Robert Lensink, and Aljar Meesters. 2011. Outreach and Efficiency of Microfinance Institutions. World Development 39: 938-48. [CrossRef]

Kebede, Hundanol Atnafu, and Wassie Berhanu. 2012. How Efficient Are the Ethiopian Microfinance Institutions in Extending Financial Services to the Poor? A Comparison with the Commercial Banks. Journal of African Economies 22: 112-35. [CrossRef]

Kereta, Befekadu B. 2007. Outreach and Financial Performance Analysis of Microfinance Institutions in Ethiopia. In African Economic Conference. Addis Ababa: United Nations Conference Center, pp. 1-30. 
Kipesha, Erasmus Fabian. 2013. Impact of Size and Age on Firm Performance: Evidences from Microfinance. Research Journal of Finance and Accounting 4: 105-17.

Luzzi, Giovanni Ferro, and Sylvain Weber. 2006. Measuring the Performance of Microfinance Institutions. Geneva: CRAG-Centre de Recherche Appliquée En Gestion.

Mersland, Roy, and Reidar Øystein Strøm. 2008. Performance and Trade-offs in Microfinance Organisations-Does Ownership Matter? Journal of International Development 20: 598-612. [CrossRef]

Mersland, Roy, and R. Øystein Strøm. 2010. Microfinance Mission Drift? World Development 38: 28-36. [CrossRef]

Pinz, Alexander, and Bernd Helmig. 2014. Success Factors of Microfinance Institutions: State of the Art and Research Agenda. Voluntas 26: 488-509. [CrossRef]

Postelnicu, Luminita, and Niels Hermes. 2018. Microfinance Performance and Social Capital: A Cross-Country Analysis. Journal of Business Ethics 153: 427-45. [CrossRef]

Rosenberg, Richard. 2009. Measuring Results of Microfinance Institutions Minimum Indicators That Donors and Investors Should Track. Washington: CGAP (Consultative Group to Assist the Poor). [CrossRef]

Servin, Roselia, Robert Lensink, and Marrit van den Berg. 2012. Ownership and Technical Efficiency of Microfinance Institutions: Empirical Evidence from Latin America. Journal of Banking E Finance 36: 2136-44. [CrossRef]

Shu, Cletus Ambe, and Bilge Oney. 2014. Outreach and Performance Analysis of Microfinance Institutions in Cameroon. Economic Research-Ekonomska Istrazivanja 27: 107-19. [CrossRef]

Tsegaye, Anduanbessa. 2009. Statistical Analysis of the Performance of Microfinance Institutions: The Ethiopian Case. Saving and Development 33: 183-98.

Vanroose, Annabel, and Bert D’Espallier. 2013. Do Microfinance Institutions Accomplish Their Mission? Evidence from the Relationship between Traditional Financial Sector Development and Microfinance Institutions' Outreach and Performance. Applied Economics 45: 1965-82. [CrossRef]

Wijesiri, Mahinda, Jacob Yaron, and Michele Meoli. 2017. Assessing the Financial and Outreach Efficiency of Microfinance Institutions: Do Age and Size Matter? Journal of Multinational Financial Management 40: 63-76. [CrossRef]

Wolday, Amha. 2004. Managing Growth of Microfinance Institutions (MFIs): Balancing Sustainability and Reaching Large Number of Clients in Ethiopia. Ethiopian Journal of Economics 13: 62-101.

(C) 2019 by the authors. Licensee MDPI, Basel, Switzerland. This article is an open access article distributed under the terms and conditions of the Creative Commons Attribution (CC BY) license (http://creativecommons.org/licenses/by/4.0/). 